\title{
Licit International Traffic in Cultural Objects for Art's Sake
}

\author{
Hugo Keith Weihe*
}

\section{Introduction}

The movement of works of art and cultural properties has at all times been beneficial to the development of new cultural values in new places and eras. There is no question that it encourages the mutual understanding and respect between people. Major historic events throughout the world have always entailed the relocation of cultural goods when victors took their tributes from the defeated. These goods were treasured and highly regarded for their level of human achievement.

In a series of lectures entitled 'On the removal of works of art from the conquered territories to Rome', ${ }^{1}$ held in Leipzig at the Casselischen Alterthümer-Gesellschaft in 1798, L. Völkel justifies Napoleon's seizure of works of art in Italy and the Netherlands at that period, by relating it to the Romans abducting sculptures from Greece to Rome. The latter had captured the sculptures of Greek gods, robbing them of their protective function in their native territories, but continued to worship them and were inspired by their artistic beauty. Now they were being captured once again to be placed in a new temple, a temple of art, the Louvre. What formerly was a standard procedure by the victorious, making hostages of the guardian gods of the defeated, had now become. a full tribute to their cultural status. To possess these great pieces naturally reflected on the grandeur, knowledge and style of the new owners, apart from being a token of their martial superiority. At no time were they interested in destroying them.

In the same year, 1798, Napoleon had taken with him to Egypt a staff of scientists who immediately set about registering the monuments and making exact drawings which some years later led to the first major publication in the field. The famous Rosetta Stone unearthed by his troops was to become the actual key to Egyptian culture when it was deciphered by François Champollion. However, in an unprecedented change of fortune Napoleon was cornered by

* Artibus Asiae, Museum Rietberg Zürich, Switzerland. 
the British, who captured the material assembled by him and transferred it to the British Museum. This institution then and now fulfilled the important function of making it easily available to the general public as well as to foreign scholars who were able to establish its cultural value in a global perpective. With some justification the director of the British Museum considers his museum a masterpiece in its own right. ${ }^{2}$ In this new context the seized cultural goods actually advanced the recognition of Egyptian culture as well as the establishment of a whole new field of science, which equally benefited the source nation. Furthermore, it spurred a whole artistic movement in France, the Empire.

This is a characteristic of all cultural transfers throughout history. If not warlords, then there are connoisseurs somewhere else in the world, who are eager to obtain foreign cultural objects. This is in the first place a tribute to the curiosity of mankind, to learn about and to cherish other peoples' achievements. A priori there is no arrogance, reckless exploitation or derogatory attitude of the politically superior, or of the 'civilized' nations towards the Third World countries. The only exceptions to this were blinded by the obvious material value, as were the Spanish faced with the gold treasures of the Aztecs, which they chose to cast into ingots. Had they known the potential market value they would certainly have refrained from this brutal act.

Cultural heritage consists of various goods that bear a distinctive relevance to a people's origin and development. The term 'national cultural patrimony' is applied in a broad sense to cultural goods and works of art created within a nation, but not necessarily by an artist of that specific nationality. This would apply, for instance, to the works of Pablo Picasso, a Spanish artist spending most of his creative life in France. At the same time he remains a unique artistic talent - as every artist essentially is - at various stages of his life venturing into new artistic realms, initially perhaps indebted to French impressionism but probably more so to African art, later truly independent - or rather becoming influential himself. It is a remarkable phenomenon that the work of an individual should become representative for a whole nation, apart from the fact that he may not even be of that nationality.

Some categories of cultural heritage, for example music and literature, stand apart for their specific properties. Although there is an original score or manuscript, they factually exist only as a performance or as printed matter, whereby the problem of uniqueness is eliminated. Without this burden and the lack of a singular material base they have transgressed all borders and in a quite straightforward way exploit their potential to become the cherished good of the world. The aspects of nationality and internationality have thereby already been overturned, without the loss of a specific identity. In view of this and with regard to the three images of the international cultural property milieu in mind, (1) 'national cultural heritage', 
(2) 'cultural heritage of all mankind' and (3) 'cultural context', why should this kind of liberation not be possible for all embodiments of cultural heritage? In the following I will choose to speak mostly of works of art, but generally imply cultural goods in a broader sense.

\section{Culture in Context}

The 'context' is the crucial point of view of the art historian. I would like to provide various aspects of this term beyond the object/context relationship as employed in archaeology.

The art historian is trained to adopt both a local historical perspective as well as a concept of 'global positioning', the assessment of mutual influences on a national and international level and crosscultural exchange. Art history is as much about individual masters as it is about anonymous workgroups, their predecessors and followers, embedded in a cultural context, whose work may or may not become a gradient, a stepping stone in the artistic evolution. One of its most powerful tools is comparison, both within a cultural context and beyond. Art itself thrives on relative values; mostly there is an element of technical accomplishment, for example of taking architectural structures to ever greater heights and more splendid decoration. But beyond that there is vision, innovation, singularity, creativity, genius. This is what we cherish and which is to the benefit of all humankind.

An interesting aspect in view of cultural importance is the fact, that cultural goods in their making are very often not recognized as such. Naturally many cases are obvious by the sheer magnitude and effort employed in the construction of objects of national status right from the start, for example the great pyramids of Giza and their contents, but there are others that are first passed by, generally 'mobile' works, like the paintings of Vincent van Gogh or the Impressionists. Still others may slip into oblivion for a while, like the works of the Pre-Raphaelites, to be rediscoverd at a later point in time. These latter cases are most interesting to our argument, stressing the volatility of judgement.

One of the crucial aspects is how we perceive art over a period of time. Why is it possible that works of art like the paintings by Vincent van Gogh were not considered to be art when they were first created and virtually unsellable at any price, only to become unchallenged masterpieces less than a century later and commanding the highest prices ever achieved by cultural goods at auction? True, the letters published by his widow revealed a powerful personality of great insight totally determined in his artistic quest and this has undoubtedly helped to form his image, but should that not have been clearly visible in the paintings themselves right from the start? How are we to know which of the goods of today are the cultural heritage of tomorrow? 
It is the liberality that has always existed in the contemporary art market - at any given time and undisputed today - that has been instrumental in the making of an artist. His work needs to be discovered, i. e. needs to be shown around to as broad an audience as possible. The collector buying from a dealer, a gallery or an auction is making a 'cash commitment', he needs to be sufficiently convinced of its quality to entail a financial suffering. This commitment to art by individuals is its status nascendi. It needs to be perceived as such and placed within its cultural context. This cultural context does not therefore exist per se, but is formed by growing consent in the relevance of an individual work for a community. More collectors might begin to compete, the prices would rise, themselves becoming an indication of value and relative importance. There is no guarantee however that a once fashionable artist might not become forgotten again, whole artistic movements (re)considered to be secondary. The failure to recognize art in the making is therefore extended by a perpetual uncertainty in its potential as national heritage. However, the more time elapses, the more precise this evaluation will probably be.

This would cast considerable doubt, for example, on the justification of considering a painting by Matisse as cultural property, particulary as the time factor becomes overly important. When does a Matisse in Italy become a National Treasure? In 1940, 50 or 60 ? The owner intending to move the painting might just miss his chance by a few years. The time element is decisive, there is movement in the perception of art and the status and influence it exerts at any given time in past, present and future.

\section{Commodification and Collecting}

Turning cultural objects into commodities is sometimes considered morally questionable. However, it is an inevitable historic fact and mostly a sign of recognition and respect. Speaking merely of speculation is too simple, there always is a relationship between market value and cultural relevance at any given time. The market is not out to destroy, but to intermediate and to supply to other more strongly interested parties. Futhermore, the market guards itself from overly excessive activities. The apparent eagerness of the art market in rich nations has encouraged fakes which to some extent act as an inbuilt protective measure for the real thing and have made many fields of collecting far less desirable, for example Pre-Columbian ceramics.

From the history of collections and the building of artists' reputations it cannot be emphasized enough how important the role of the private collector is as the main driving force of artistic discovery. At the initial level of collecting there is no restriction, but why should the fruit of individual connoisseurship eventually result in a 
ban? Should the collector not be entitled to profit from rising market values and to freely dispose of his property.

In Europe, since the Renaissance, many works were not only created by commission, but for a free market. Art became a highly unique product, the work of a gifted individual, as opposed to a group-effort or the work of a nameless craftsman. The notion of artistic genius became apparent. The pricing for art gradually shifted from purely technical aspects, as the cost of the pigments involved and the total labour employed, to the aspect of artistic quality. Albrecht Dürer argued in the case of the so called 'Heller-altar', 3 that the more time he would invest in this commission the finer the result would be - thereby trying to coax out an extra 100 guilders from his client. ${ }^{4}$ Essentially he was not willing to compromise his artistry by a modest price level. This awareness of market value on the part of artists, culminating in the contracts between the Paris art dealer Daniel-Henry Kahnweiler and Picasso, Braque, Gris, Leger and others in the early 1900 s, guaranteeing them a certain sum per canvas of a specific size, established art in the making as a commodity.

The history of the making of an artist generally proves that the dealer who makes works available and assembles exhibitions and the private collector who buys from him are instrumental in this process. To discredit the private collector would be equally detrimental to the public interest, as museums heavily rely on donations from private sources. To that extent, private collections very often represent an intermediary state. The private collector, as opposed to. any institution, is only responsible to himself, drawing on his own funds and therby generally being far more enterprising and taking greater risks. A museum, as a rule, has to reach a decision within a large premium and be in a position to publicly justify any acquisitions. This will often prevent it from acquiring avantgarde art at an early stage. The image of the private collector might have been tinged by the avaricious approach, particularly in the eighties, of investors new to the art market, but the true collector still is the carrier of connoisseurship. It should not be forgotten that works of art very often are highly individualistic products and likewise require a personal approach.

It is a false conception to believe that by becoming a sellable commodity a cultural object ceases to be an object of cultural identity. Naturally its actual cultural value cannot be priced; none the less it has a market value at any given time which may vary according to location. If 'commodification' is an inevitable attribute, it is by no means a priori detrimental. At any time the actual or potential market value is an indication of the importance of a given cultural object or of its momentary perception..$^{5}$ Most importantly the status of works of art has been established by their effective or potential market value reflecting back on them. The market offers a managable reference to relative values between objects. Without trade art would only have an intrinsic value. The market-place does not neces- 
sarily spoil the objects or their aura, high prices rather reflect their very special status.

The trade actions of Peter Paul Rubens provide a fine example of the workings of artistic exchange and the total lack of any negative connotation. Through his achievements as a painter and his diplomatic skills Rubens became an influental political figure conversing with the powerful people of his time. Being himself a collector of antiquities, he longed to acquire the collection of Roman antiquities of the British emissary to Holland, Sir Dudley Carleton. He set about in 1618 offering his own works in exchange, some of which he had sold previously and bought back at higher prices, thereby underlining their importance. ${ }^{6}$ An agreement was ultimately reached, in which Sir Dudley accepted a number of paintings up to a specific total value, insisting on the difference being made up by Gobelin tapestries, a highly prized good at that time. Subsequently both parties parted again with their newly acquired treasures, Sir Dudley offering the Rubens' to the King of Denmark, Rubens being asked by the infanta Isabella of Spain in a move of appeasement with England to pass on his collection to the Duke of Buckingham, to which he obliged. Both the paintings by Rubens as well as the antiquities are cultural goods today. The status of tradable goods they enjoyed in the past not only asserted their importance, but helped alleviate political tension.

A distinction should therefore be made between these 'mobile' cultural goods, and those commissioned for a specific function. A vast majority of the cultural goods handled in the art market will at one point become part of a public collection. Private collectors, seen in a historic context, are part-time owners.

The main concern is for archaeological and ethnographical material which is most prone to looting. The fact that there is a demand for archaeological objects is in line with the general interest in all cultural artefacts and should neither be condemned nor indeed suppressed. The market, the private collector as well as institutional collections, are to some extent the driving forces for further discoveries. The uncovering of hitherto unknown cultural objects furthers the general knowledge. There is no question that excavations today must be undertaken in controlled conditions to ensure the object/context image. However, once this has been established and recorded, there is no immediate reason why objects should not be dispersed other than that they should remain together to form a study collection. It could be argued that without the outlook of marketability, many excavations could or would not be undertaken.

Any art historian, particularly so in a museum, must be interested in the furthering of public interest, knowledge, and awareness of cultural values. The more material surfaces, the better. The denial of expertise to pieces of questionable source by experts and scholars would boomerang scientific advance, apart from the fact that 'embargos' of this sort never work in a global perspective. Naturally there can be no interest in a black market, where objects submerge 
and thereby pass scientific recognition. A possible way of preventing this might be the encouragement of private enterprise in supervised land excavations, as has been practised in shipwreck incidents. The incentive would be a share in the potential hoard, at the discretion of the responsible government.

There is a certain irony in the fact that sporadic finds and illicit trade brought things to light and initiated scientific research and artistic evaluation. For example Max Loehr correctly established the development of archaic Chinese bronze styles in the Shang period based on careful observation of existing objects of which most had no record, just by deducing a logical sequence of development. ${ }^{7}$ Many objects had been found by farmers ploughing their fields in the vicinity of ancient tomb sites, who would later sell them in the market place, where subsequently all traces of origin were lost. His analysis supported by theory alone, which was no easy task, proved to be correct based on pieces later found in controlled excavations in Hunan province.

The fact that the nationalist image dominates in Third World source nations notably has to do with the fact that they have been exploited and have not profited financially to the full extent. If they have been stripped of their heritage almost completely, there will have to be some consideration placed in the restitution of individual pieces by a body like UNESCO. Otherwise, the solution can only be to further awareness and knowledge locally to guard what remains. However, there must be a strict line of conduct to avoid a doublefaced approach. In a phase of economic strain there must not be any semi-official sale of works formerly considered 'national heritage' in an attempt to alleviate this condition. There is to be no tolerance of clandestine excavations in order to profit from commissions.

\section{Exchange and Perception}

The mutual understanding between people and above all, the 'Common Heritage of Mankind' (CHOM) are concepts strongly supported by the UNESCO. Both in effect strengthen the argument for a liberal approach of exchange.

Ever since the times of Albrecht Dürer, prints of all kinds have become a very effective means of distributing art and the knowledge of cultural achievements. Today, in the age of luxurious book publications with beautifully printed colour plates throughout, the status of the original work has changed. Masterpieces thereby become generally known and are accessible from all over the globe, in some cases already via electronic databases. However, there can be no doubt that the ability to reproduce cultural goods, both physically as well as in high quality photographs, always fails to substitute the original, as its 'aura' and uniqueness in time and location ('hic et nunc') remain irreproducible. ${ }^{8}$ Only an original has the attributes of a cultural property. The high level of mobility we enjoy today can 
never make up for actually having works in our immediate vicinity or even living with them. Still, the increasingly easy access through various media might justify a reconsideration of this position, particularly in an era of computerized communication and the concept of the world as a 'global village'.

Cultural exchange should not just be left to acts of war. Exchange and dislocation is a strong driving force in the making of cultural values, if not a catalyst in cultural evolution. Probably every culture in history has profited from foreign imports influencing and affecting the perception of its own culture. African cultures adopted new shapes and utensils brought to them by the Portuguese, while African masks triggered the development of cubism in France. Persian scrollwork was adopted by the Chinese in the Yuan period blue-and-white porcelain which in turn became highly prized collectables in Persia, whereby influences and goods were exchanged via the silk route.

Just as their works, the creators of cultural goods may potentially profit from moving around, as naturally every artist is strongly influenced by his surroundings. So he might sometimes precisly choose to escape in search of new input: for example, Van Gogh moved from Holland to Paris and then to the south of France. His dark early works were now replaced by much brighter ones. The vivid colours he experienced in the vibrant sun of the Provence were most beneficial to his artistic development, but more striking is the fact that he described this landscape as his personal view of Japan, ${ }^{9}$ a far more distant culture of which he formed a vision through the colour woodblock prints that had been introduced to the Western art world around the mid 1850s. The strong colours he found in these 'offprints' from the land of the rising sun had led him to this belief. It might therefore be said that a high level of liberality in exchange of goods, thoughts and visions is often instrumental in an artistic process.

Why not pledge for an interchange of cultural property on the basis of loans? After all, among the most successful exhibitions today are the blockbusters bringing together the output of a lifetime of the likes of Braque, Cezanne, Picasso, Rembrandt, to name just a few. It might therefore even be argued that it would appear more practical if these works had always remained together. But Van Gogh or Picasso would certainly not be the internationally renowned masters they are today if their work had not been distributed worldwide and thereby granted the opportunity of being viewed and discovered internationally. Today, the exchange of loans of cultural objects is becoming increasingly difficult. Many objects are too fragile or too unique in their importance to risk frequent dislocation, apart from the insurance premiums and the cost of safe transport being prohibitive. While this may be seen as a repercussion of the art market, it is foremost an account of the importance of each work.

At all times contemporary art is exempt from any restrictions. Age barriers concerning cultural goods are set at fifty or one hundred 
years, but are purely technical measurements lacking actual justification. The making of a cultural object is fluent and not determined by precise age barriers. At one time all cultural products were 'contemporary'. Because they have not yet proven their cultural importance, they cannot be looked back on and seen within a cultural development. They are granted total freedom so that they can prove their importance - and rightly so, although this would appear inconsistent from a protectionist point of view.

Spreading also guarantees a higher level of survival of cultural objects by distributing the risks of destruction by natural causes, by vandalism or theft. The keeping of cultural objects in their source nation alone does not guarantee the best rate of survival, on the contrary. Naturally this does not just apply to Third World source nations.

Finally, it could be argued that strong protective measures as implied by the UNESCO convention to some extent damage cultural objects by making them untouchable ('noli me tangere'). They might thereby lose a certain degree of accessibility within a source nation most interested in preventing this.

\section{Conclusions}

Foremost, it is imperative to further strengthen the awareness of all peoples of their own local heritage, to further education, knowledge and ethics in all fields including culture in a broader perspective.

With regard to archaeological excavations it is vital for governments to gain control, in order to conduct them with the necessary care and to record existing objects and the context of those yet to be discovered. In order to assure this, a certain amount of private enterprise in this field could be considered along the lines drafted. Even looters and smugglers could be trained to use more care and develop more knowledge, as the financial rewards are greater the better the condition of an object and the more they are aware of its importance.

Blaming destruction of monuments in Third World countries on a receptive market in the rich countries focusses away from the lack of necessary control in the countries themselves. Preventing clandestine looting by killing the market might prove an uphill battle rather like fighting drug abuse. The causes of collecting cultural goods are generally noble and not detrimental to health or a financial burden to society.

Rules as expressed by the American Journal of Archaeology not to publish any works that have not knowingly been in a collection for more than thirty years prior to the 1973 rules could backfire in the sense that important but illegally exported works would have to be withheld from general knowledge, thereby seriously hindering scientific advance. 
With regard to the concept of 'global treasures', the preservation of each cultural object would be of foremost importance. It would therefore be necessary to assure its best possible protection in the safest available haven wherever that might be. After controlled assessment of its historic context, it should be made generally available and placed in the most suitable surroundings regarding accessibilty.

Regulations for the movement of cultural objects should be as simplistic and unbureaucratic as possible. The British and Canadian export regulations appear to be the most workable as they respect the workings of the art market. The long tradition in the sale of works of art through auctions in England has established a liberal approach. The problem of Third World countries often being unable to afford buying back their own cultural goods would be alleviated, if they were to sell goods under controlled conditions and fully documented at their true market value. This would also be a way of assuring true exchange, allowing them to acquire cultural goods from other source nations.

Art has always flourished by exchange. We are obliged not only to look back, but also to look forward. Cultural objects should be allowed to be there where they are most treasured and can unfold their greatest potential.

\section{Notes}

1 L. Völkel, 'Über die Wegführung der Kunstwerke aus den eroberten Ländern nach Rom, Eine Vorlesung in der Casselischen Alterthümer-Gesellschaft gehalten von L. Völkel,' Leipzig, 1798.

2 Cf. Sources UNESCO, no. 28 (July/August 1991), p. 11.

3 Commissioned from the artist by Jakob Heller in 1507 and destined for the Dominican church in Frankfurt am Main.

4 Cf. Hugo Weihe, 'Künstlerische Qualität und Marktwert,' Diss. phil., Zurich 1992, pp. $15 \mathrm{ff}$.

5 It is important to consider these values as relative rather than absolute. For example, according to present legislation, the same Matisse painting might be 'worth' less if it were in Italy rather than in England, for the fact that it cannot be moved. This fact would be reflected in its market value.

6 Jeffrey M. Muller states: 'Through his active choice and seeking out, Rubens became, in effect, a collector of his own work.' in 'The artist as collector,' Princeton 1989, p. 15.

7 Max Loehr, 'The Bronze Styles of the Anyang Period,' Archives of the Chinese Art Societ of America, New York 1953, VII, pp. 42-53.

$8 \mathrm{Cf}$. Walter Benjamin, 'Das Kunstwerk im Zeitalter seiner technischen Reproduzierbarkeit,' Gesammelte Schriften, Vol. 1, Frankfurt am Main, 1974.

9 Van Gogh expresses an admiration for Japan and Japanese colour woodblock prints in various letters to his brother written in Arles between 1888 and 1889 , cf. Johanna Gesina Van Gogh- Bonger (Ed.), Vincent von Goghs Briefe an seinen Bruder, Frankfurt am Main 1988, Vol. III, pp. 340, 342, 385, letters $526,527,540$. 